\title{
Exploring the Sociolinguistic Aspects of Sinhala-English Code-Mixing among Urban Sri Lankan Bilingual Speakers
}

\author{
Hakmana Pranara Liyanage Waruni Shashikala \\ Department of English Language Teaching, University of Sri Jayewardenepura, Colombo, Sri Lanka \\ Email: shashikala@sjp.ac.lk
}

How to cite this paper: Shashikala, H. P. L. W. (2021). Exploring the Sociolinguistic Aspects of Sinhala-English Code-Mixing among Urban Sri Lankan Bilingual Speakers. Open Journal of Modern Linguistics, 11, 158-173.

https://doi.org/10.4236/ojml.2021.112014

Received: February 7, 2021

Accepted: April 6, 2021

Published: April 9, 2021

Copyright ( 2021 by author(s) and Scientific Research Publishing Inc. This work is licensed under the Creative Commons Attribution International License (CC BY 4.0).

http://creativecommons.org/licenses/by/4.0/

\begin{abstract}
Language mixing has become a natural phenomenon in the spoken discourse of the urban Sinhalese-English bilinguals today. This study examines how and why they mix codes from a sociolinguistic perspective and analyzes the structural properties of such code-mixing (CM) found in their speech. This study follows a descriptive qualitative method. This is qualitative since this depends on data that include words, phrases and sentences and is descriptive since it provides an accurate factual description of a setting. The sample comprised 30 bilinguals from the employed bilingual population in the main urban city of Sri Lanka due to their frequent use of the mixed-code in conversation. For a comprehensive analysis of the sociolinguistic aspects of the respondents' speech, a sociolinguistic questionnaire based on the four discourse strategies: foregrounding, nativization, hybridization, and neutralization as proposed by Kachru (1978/1983/1986) was used. For the structural analysis, their spontaneous speech was recorded, and the framework of Muysken (2000): insertion, alternation, and congruent lexicalization (CL) was used. The findings report that this mixed-variety has evolved due to CM and is undoubtedly the preferred code for expressing neutralization of attitudes in speech. Further, their language choice seems to have been influenced by the age. Structurally, this discussion proves insertion as the major CM strategy in the bilinguals' spoken variety, while $C L$ is the least used. From a pedagogical perspective, this study proposes $\mathrm{CM}$ as a possible communicative strategy to promote interaction among students in the second language learning-teaching context in Sri Lanka.
\end{abstract}

\section{Keywords}

Code-Mixing, Second Language, Foregrounding, Nativization, Hybridization, Neutralization 


\section{Introduction}

More than twenty decades of contact with a foreign language has resulted in a large number of lexical items being mixed by urban bilingual speakers in Sri Lanka in their daily conversations. Today, Language mixing among Sinhalese/Tamil-English bilinguals has become a common and natural phenomenon.

Apparently, there is a major linguistic change reflected in the post-colonial Sri Lankan society in terms of Sinhala and English languages. This change has subsequently given birth to a mixed code. As Disanayaka (1998: p. 133) describes, "The English rulers left behind, among other things, their language, English, which the Sinhalese have moulded in their own way. This brand of English may legitimately be called 'Sinhalese English"'. Although this used to be a highly criticized and undervalued practice, it has now become a characteristic of the native Sri Lankan bilingual's spoken discourse. As Wettewe (2009: p. 3) states,

" $\mathrm{CM}$ is and has become an essential feature of the identity of the post-colonial urban Sri Lankan.”

A typical instance of the said mixed variety in speech is:

"fry karala cook karanna" (first fry and then cook).

Apparently, code-mixing (CM) is heading towards a permanent place in written contexts too.

As far as the phenomenon of CM in Sri Lanka is concerned, it can take place either way: the use of English words when conversing in Sinhala or vice versa. This study deals with speakers who mix Sinhala and English linguistic items in the utterances they produce in the domains of morphology, phonology, and syntax.

It is very natural for Sri Lankan bilinguals to mix both single words and complete utterances from the two languages and the strategies employed by these speakers can be identified as insertional, alternational and Congruent Lexicalizaton (CL) (Muysken, 2000).

The proposed study has been structured to answer the following research question:

From a sociolinguistic perspective, how and why do urban Sri Lankan bilinguals (Sinhala-English) mix codes in conversations and, what structural properties of Sinhala-English CM are found in their speech?

Other than the introduction which describes the subject matter under investigation, this study includes three main areas. The second section involves an account of related literature on the phenomenon of $\mathrm{CM}$ in general and $\mathrm{CM}$ as a common linguistic practice among urban Sri Lankan bilingual speakers whose native language is Sinhala in particular; third is research methodology and theoretical framework which highlights the methods of data collection and analysis; fourth is analysis of data and discussion of findings followed by conclusions and implications. 


\section{Theoretical Background}

This provides a comprehensive review of literature about the theory and research in the area that underpin the study under investigation. This focuses altogether on three areas of study: phenomena of CM, CM among Sinhala-English speakers in Sri Lanka, and research on CM in and out Sri Lanka.

\subsection{Code-Mixing in General}

In many countries, $\mathrm{CM}$ is a well-documented process in the speech of bilingual or multilingual speakers though their reasons for CM vary. According to Muysken (2000: pp. 1-8) these speakers tend to choose one type of CM in speech depending on syntactic elements as well as sociolinguistic \& psycholinguistic factors. He distinguishes three types of code-mixing: insertion, alternation and congruent lexicalization. Exploring the said phenomena and its manifestation in language contact, these concepts have been established. They are used in the present study in order to explore the functional uses of CM in Sri Lanka. "Insertion" involves placing lexical items or entire constituents from one into the structures of the other of the languages concerned as in:

A-na-ku-l-a plate m-bili z-a murram

"He eats two plates of maize." (Swahili-English/Myers-Scotton, 1993: p. 86)

Whereas "alternational mixing" is identified as occurring in two languages where the syntax is largely shared though the vocabulary is different as in:

I mean, ganti ke kalimat lean.

"I mean, change it to another sentence." (Indonesian-English/Claros \& Isharyanti, 2009: p. 70)

Muysken (2000: pp. 1-8) illustrates "Congruent Lexicalization" as occurring when "the grammatical structures are shared by languages A and B, and words from both languages $\mathrm{a}$ and $\mathrm{b}$ are inserted more or less randomly.” As in:

Apee compaeni-yen.

From our company (Wettewe, 2009: p. 158).

\subsection{Code-Mixing among Sinhala-English Speakers in Sri Lanka}

Naturally, the use of two languages by the same speaker almost inevitably affects the languages so concerned. Over generations, this language contact has led to the functional elaboration of both Sinhala and English. The use of English and Sinhala by Sinhalese speakers has led to a mixed variety and CM is one of its salient features. Today, CM in Sri Lanka is an obvious expression of being bilingual and integration of languages in conversation is now a characteristic of their speech. In fact, it is no longer considered derogatory, absurd or unskilled and this mixed- code is "... rule-governed, maintaining that it has inherited structural elements from both Sinhala and English ...” (Wettewe, 2009: p. 11). This study focuses on the mixing context that involves Sinhala and English spoken 
among Sinhala-English bilinguals in Sri Lankans.

\subsection{Reasons for Code-Mixing: Sociolinguistic Aspects}

Recent research on the phenomena of code-mixing in Sri Lanka has revealed that bilingual speakers use the said mixed variety for definitive purposes. As Wettewe (2011: p. 17) states, they use a mixed code for the following: Foregrounding, Neutralization, Nativization, and Hybridization.

According to Kachru (1986: p. 59), the process of foregrounding refers to bilinguals' use of a mixed language for attracting attention to or emphasizing a particular meaning conveyed. As he defines, "The aim in neutralization is to use lexical items from English, which are not loaded terms." (Quoted in Wettewe, 2009: p. 95) Quite exclusively he describes how Indians use English lexical items which are culturally and socially neutral and how successful the whole process has been. The process of nativization simply means that linguistic elements from the alien language are nativized or integrated into the native language in a contextually appropriate manner without harming the rules and norms of the languages involved, states Kachru. (Quoted in Wettewe, 2011: p. 48) Many Sinhalese use the mixed variety for hybridization. They tend "to expand or extend the vocabulary in the" mixed variety.

\subsection{Singrisi vs. Singlish: Language Analysis}

Considering the mixed language of Sinhalese bilinguals Fernando notes, "The most striking feature marking the use of English and Sinhala in present-day Sri Lanka is the invasion by Sinhala of almost all the areas held by English alone." (Quoted in Fernando et al., 2010: p. 227) A wonderful example that illustrates the above said is the extract taken from Daily Mirror, October 27, 2004:

“... Hatti, mutti, manioc plants and polos were carried in the protest march

while ....” (Quoted in Gunesekera, 2010: p. 69).

Here, quite interestingly the words Hatti, mutti (pots) and polos (jackfruit) are not used in glosses and these instances indicate that such Sinhalese words have become a part of the mixed variety.

In Understanding the Sinhalese, Disanayaka (1998) shows a typical example of the impact of English on speakers' informal conversation. Simultaneously, it proves that the fact that it is governed by its own rules and system has made it a "linguistic reality" in the country.

“... Namut samahara tutors-la kiva lectures cancel karala practical vitarak

karamu kiyala. Lectures cut-karana undergraduates-la kavadat fail-venava."

(Disanayaka, 1998: p. 134)

But some tutors said that they would wish to cancel lectures and do only practical work. Those undergraduates who cut lectures fail anyway.)

Here, Disanayaka explains how Sinhalese add "la" to words in English to form plural animate nouns in their speech. 
The above shown instance can be regarded as significant developments of the mixed language variety used by Sri Lankan Sinhala-English bilinguals.

\subsection{Research in Code-Mixing}

A considerable body of research has been carried out by linguistic researchers to examine the phenomena of code-mixing among multilingual speakers around the world. This section consists of five studies conducted to explore the sociolinguistic and structural properties of code-mixing in conversation. These investigations are extremely important for the present research because they cover a wide range of aspects to be covered in this study.

- Many influential studies on the phenomena of code-mixing in former British colonies were conducted by Kachru (1978/1983/1986). His definitions of the process of nativization, hybridization, neutralization, and Englishization are given much consideration in this study. His observation about the code-mixing varieties in India heavily influenced the present study. He focuses mainly on the functional aspects of code-mixing and as he states, the mixed-variety that has evolved is another variety that is now very commonly used by multilinguals.

- An extremely important framework for code-mixing patterns has been proposed by Muysken (2000). His investigations about occurrence of code-mixing patterns in bilingual speech are considered highly important to the present study. As he states, three models can be utilized rather than using one model for all language pairs and bilinguals choosing of one type of code-mixing depends largely on structural and sociolinguistic aspects.

- Another study by Gunesekera (2010) provides an overview of the phonological, morpho-syntactic, and semantic characteristics of SLE. Drawing on data collected over a period of 15 years, she focuses on the structural properties of the varieties of English spoken in the post-colonial Sri Lankan setting, and reports $\mathrm{CM}$ as a discourse strategy among Sinhala-English bilinguals.

- Another study carried out by Karnalasuriya (2008) discusses the phenomena of code- mixing among Sri Lankan bilinguals and the use of "Singrisi" in particular. From a socio- functional perspective, this study proposes that Sinhala-English bilinguals practice code- mixing for the definitive purpose of expressing modernization, and concludes that the characteristic of code-mixing has now become a threat to the native tongue.

- Wettewe's analysis (2009) focuses on the sociolinguistic aspects of code-mixing in the post- colonial Sri Lankan setting and presents a comprehensive analysis of the structural properties of the mixed language that has become a linguistic reality. She concludes that a mixed variety has evolved as a result of the language contact between Sinhala and English, and that this variety is mostly influenced by the first language.

\section{Methodology}

The research design of this study is descriptive qualitative method. This is qua- 
litative since this is based on data that include words, phrases and sentences and is descriptive since it provides a systematic, accurate and factual description of a situation or setting (Issac \& Michael, 1987: p. 42).

\section{Instrumentation \& Sampling}

In this study, two types of data were collected. For a comprehensive analysis of the sociolinguistic aspects of urban Sinhala-English speakers' speech, the researcher made use of a sociolinguistic questionnaire. This was a modified version of that used by Wettewe (2009). The researcher uses four discourse strategies: foregrounding, nativization, hybridization, and neutralization as proposed by Kachru (1978/1983/1986) in collecting data from the mixed- language of these bilinguals in order to explore the sociolinguistic characteristics of urban Sri Lankan bilinguals' CM. Here, data were collected from 10 bilingual respondents who came from five urban areas of Colombo, a main-city in Sri Lanka. All these respondents received their entire education in local government schools. Further, they use many languages and varieties such as Sinhala, Sri Lankan English (SLE), Singrisi (English in Sinhala), and Singlish (Sinhala in English), both at home and work, and all of them belong to the urban middle class. The researcher decided to draw a sample from the employed bilingual population since these speakers were the most frequent users of the mixed-code in their everyday conversation.

For the structural analysis, these respondents' spontaneous speech was recorded and data were collected from them over a period of two months. In order to analyze the structural properties of urban Sri Lankan Sinhala-English bilinguals' mixed language, this study utilized the framework proposed by Muysken (2000). Similar to what has been proposed by Wettewe (2009), the present study insists that most of the elements of the said variety can be explained by Muysken's CM typology.

\section{Findings and Discussion}

This section reports the findings of this study followed by a discussion. The overall aim is to seek the sociolinguistic and structural aspects of code-mixing in the urban Sinhala-English bilingual. Firstly, this explores the sociolinguistic setting of the present study in detail. More precisely, the study examines the sociolinguistic characteristics of urban Sinhala-English spoken discourse in Sri Lankan and the reasons for their CM, and how far this mixed-code is sociolinguistically embedded. Kachru's framework (1986) for CM was used mainly for this analysis.

\subsection{Sociolinguistic Analysis}

\subsubsection{Language Choice \& Different Domains}

This reveals the findings of the present study in terms of the respondents' language use in four core domains in their daily routine. This illustration largely depends on the analytical framework of Wettewe (2009) and Table 1 (Appendix 
1) provides data regarding such behavioral characteristics.

Interestingly, the use of Sinhala-English is marked with high percentages in many domains though a very low rate is recorded in the religious domain. However, the domain data presentation reports English as the least used code at temple (all these informants are Buddhist) whereas their mother language is recorded with the highest rating in the religious domain. The findings reveal that the mixed-code plays a dominant role in many of their informal domains and surprisingly, this alternate-code is becoming a characteristic of their formal domain too. The fact that this variety is projected with high ratings in almost all the domains indicates that the mixed- discourse has replaced the native tongue mostly in many domains, similar to the outcome of Karnalasuriya's research (2008).

\subsubsection{CM as a Foregrounding Strategy}

According to the theory of foregrounding, proposed by Kachru (1986), CM in the informants' spoken discourse in these domains provide evidence of it being used as a registral or style function. Their responses reveal that native Sinhalese use English items widely in dominant Sinhala utterances in domains of power or their preference to use elements from a high code whereas mixing with Sinhala occurs since they have a tendency to use items from a low code. Sociolinguistically, this mixing strategy is used for different purposes. Proficient speakers of both English and Sinhala mix-codes for purposes of sarcasm, humour, conspiracy, and intimacy though the latter is identified as "derogatory" (Disanayaka, 1998: p. 133) by some speakers. Such lexica items from Sinhala are socially and culturally so integrated in the Sri Lankan setting that speakers of English in this context spontaneously insert them in their English utterances. These, items have now become a part of SLE.

\subsubsection{Hybridization \& Nativization}

A majority of urban Sinhala-English bilinguals phenomenally use the mixed-code in their daily conversations. Such formations are frequently used by Sri Lankan bilinguals in the domains of religion, politics and culture. Over time, hybridization \& nativization have evolved as common characteristics of CM in Sri Lanka. These terms are hardly motivated by loan translation, as Wettewe describes, because they are no longer considered deviant. The informants' responses show that these speakers use hybrid terms in which Sinhala and English are closely integrated and this is as Wettewe (2011: p. 43) insists "a direct result of CM." As it has been described by Wettewe (2011: p. 51), such hybrid constructions have been labeled as "Sri Lankanisms." As these respondents claim, the extensive use of $\mathrm{CM}$ in spoken discourse has resulted in the creation of many compounds. Both include elements from both languages: Sinhala \& English. However, in hybrids, the influence of English on dominant Sinhala utterances is found, where as in nativized items, the dominant influence of Sinhala is evident. Similar to Kachru's (1983) explanation, hybrid compounds are being practiced as a marker of some deliberate style and modernization as in: 


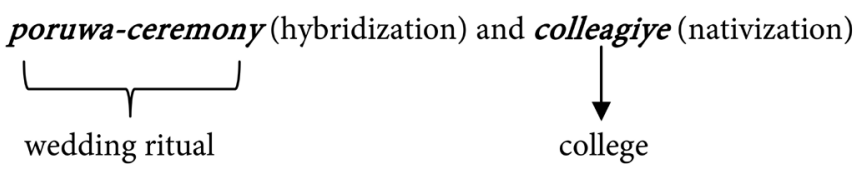

\subsubsection{Attitudinal Characteristics of the Respondents}

There is a preference for the use of both languages in these respondents' spoken discourse and is out spoken in the government sector employees. This has been caused by their positive views towards a mixed-code as the most neutral language for their informal speech. According to Kachru's theory (1983) of neutralization, they seem to have an overwhelming preference to use an alternate-code as a way of expressing that they are attitudinally neutral. Data from the questionnaire and recordings illustrate that the informants use lexical items from English and replace Sinhala elements which are culturally loaded terms.

Interestingly, the use of Sinhala-English bilingual speakers as in Table 1 (Appendix 1) mainly by those who frequently use their mother tongue as the medium of instruction at work indicates that this alternate-code in which English items are integrated in to dominant Sinhala utterances has built integration between native Sinhalese and English speakers in the post-colonial social setting. Very similar to Karnalasuriya's study (2008), these speakers' longing for a neutral language indicates a shift in terms of attitudes taking place in the social scenario of the country. Surprisingly, the attitudes of these informants suggest that these bilingual speakers use the mixed-code with similar functional values as Sinhala. Sinhala is quite often replaced with the mixed-language and their attitudes give the connotation that they naturally and successfully use CM to integrate English elements with Sinhala utterances. As Wettewe (2009) explains, the mixed-code overlaps with the use of Sinhala.

An observation of their preference for a mixed-code in the media proves the mixed-language preference over a monolingual particularly in informal speech. Also, these informants' responses indicate that $\mathrm{CM}$ is practiced even among professionals because many English lexical items hardly have their Sinhala counterparts or such Sinhala terms are not naturally or frequently used by the native Sinhala speaker. A majority insists that such Sinhala lexical items are not used in their spoken discourse and English terms are now so integrated into Sinhala utterances. Similar to Sailaja's (2011) study on Hinglish, this sociolinguistic analysis proposes $\mathrm{CM}$ as the alternate code to be used by Sinhala-English speakers in both formal and informal contexts.

Based on the significant data revealed in this section, it is clear that these bilingual speakers neither deny the phenomenal and common use of CM in both public and private settings, and nor they deny that this has become a common characteristic of the bilingual spoken discourse in Sri Lanka today. Undoubtedly, "Singrisi": English items in dominant Sinhala utterances, is the widely used and it governs the spoken mixed-discourse.

\subsubsection{Age Factor \& Language Choice}

A majority of the respondents belongs to the age group of 24 - 35 years and they 
seem to show a tendency to use the mixed-code in many domains in urban Sri Lanka. This particular age group has shown their enthusiasm towards the mixed-language, and sociolinguistically, this has been caused by their keen interest to be associated with a particular culture or social norm. Similar to the findings of Wettewe (2009), these responses place much emphasis on the relationship between age and language preference and language choice seems to depend largely on age factor. According to the findings reported in Table 1, the influence of age is very likely to be on their language choice.

\subsection{Structural Analysis}

The structural analysis of this study largely depends on the framework of CM strategies proposed by Muysken (2000): insertion, alternation, and congruent lexicalization. As Muysken states, structural properties of the languages concerned play a vital role in deciding the type of CM strategy to be followed when mixing codes. This illustration deals with the findings of data collected from recorded spontaneous conversations of the sample and provides an overview of the phonological, morpho-syntactic and semantic features of Sinhala-English $\mathrm{CM}$ in spoken discourse and how such features are structurally integrated in the mixed-code. In this study, the analytical structures of Wettewe (2009) \& Gunesekera (2010) are also followed.

In the post-colonial Sri Lankan setting, Sinhala possesses dominant status whereas English is the most influential language. Data presentation reveals that informants' Sinhala-English CM in dominant Sinhala utterances is more frequent than in English conversations. Based on Muysken's theory single and multi-word mixes are categorized into those CM patterns and their structural integration within those utterances is thoroughly analyzed here. It has to be noted that this study, similar to Wettewe (2009), promotes Muysken's interpretation that "borrowing exists in all the mixing strategies."

\section{"Singrisi" \& "Singlish"}

Results for CM of Sinhala-English participants show a variety of English items integrated into Sinhala utterances. Although not equivalent to the frequency rate of CM occurrence in Sinhala utterances, Sinhala lexical elements are also integrated into dominant English utterances. In general, these utterances prove that they have been phonologically as well as morpho-syntactically shaped by language change. Such embedded English elements are mostly nouns, noun phrases, verbs, and verb phrases. Based on the data gathered for the structural analysis, different types of mixing strategies can be identified.

\section{1) Insertion}

A majority of elements found in the mixed-code are insertions. Frequently, the spoken discourse of Sinhala-English bilinguals includes many inserted singular English nouns, noun phrases \& verbs followed by Sinhala particles such as eka, ekak (with English inanimate nouns) and kenek (animate ones) in Sinhala conversation. In colloquial Sinhala, these are phenomenally recurrent and are 
very productive in terms of nominalizing capacity. Also, English plural inanimate nouns are placed before Sinhala verbs. Further, English plural nouns are followed by Sinhala compound verbs in dominant Sinhala utterances and a large number of English verbs are followed by "karala".

These are clear indications of Muysken's (2000) insertional strategy. Similar to Wettewe (2009), they have been the result of Sinhala-English CM as in:

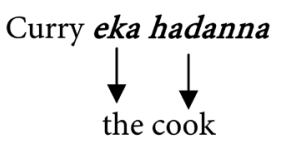

Lovely decoration ekak karanna

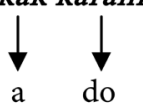

Curries uyala yanna.

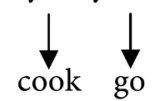

Fix karala thiyanna

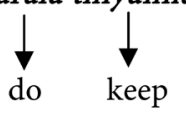

Findings show many instances where speakers replace "the tag" in English with Sinhala "needa" which occurs either sentence centrally or finally in English utterances as in:

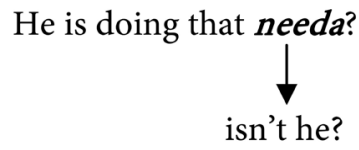

This is considered a typical example of SLE syntax, similar to Gunesekera's (2010) findings. Further, many participants have used Sinhala compound nouns sentence finally in the spoken discourse and similar to Gunesekera (2010), the results reveal compounds in the mixed-code as highly productive and a part of "Singlish" due to CM as in:

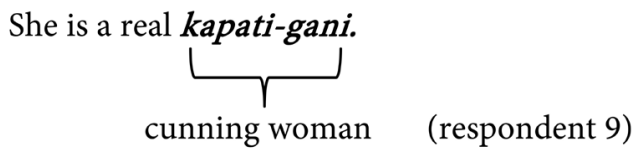

The above discussion justifies Muysken's (2000) proposal of insertional CM.

\section{2) Alternation}

Compared to insertional CM, patterns that exhibit Muysken's (2000) theory of alternation are less frequent than insertional mixing in the mixed-code. The bilingual corpus includes alternation of complete constituents and unlike in the insertion and CL, a linear equivalence exists in the use of English and Sinhala in the mixed-variety as in:

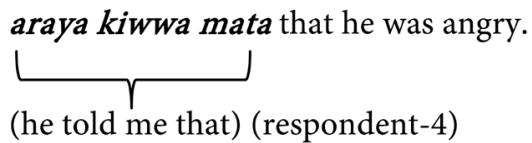


Often, adverbial phrases, reduplicated adverbs, and clauses from English \& Sinhala are integrated into and juxtapose against in their mixed-utterances. Such alternational patterns are often placed sentence finally. These lexical items in the mixed-variety may or may not display grammatical coherence among them. This study promotes Gunesekera's (2010: p. 133) investigation of the phonological and morpho-syntactic elements of SLE and her claim "mixing is a growing tendency."

\section{3) Congruent Lexicalization (CL)}

The results reveal that CL is perhaps the least utilized CM strategy in the bilingual corpus. Quite often, English nouns are nativized into Sinhala utterances by adding Sinhala suffixes and this nativization process, known as Sinhalization, reveals some significant phonological characteristics of the mixed-code in Sri Lanka as in: packaga-yen (package), ischool (school), and ispecial (special). The speakers have inserted /i/ to nativize these lexical items and they now possess permanent status in dominant Sinhala sentences. Interestingly, English lexical items have been adapted both phonologically and morpho-syntactically into mother variety as a result of CM. These adaptations follow the traditions of Sinhala often since it is the dominant figure in the mixed-code and such are known as "Lankanisms" (Wettewe, 2009: pp. 52-54). CL hardly occurs in dominant English utterances.

\section{Conclusions and Recommendations}

In this section, some implications and suggestions that have been drawn from this study will be presented. This study examines the phenomena of CM by urban Sinhala-English bilingual speakers which is no longer considered deviant and absurd. Data collected from the sociolinguistic analysis and structural analysis of this study answer the research question:

How and why do urban Sinhala-English bilinguals mix codes in their spoken discourse and what structural properties are found in their mixed-code?

\subsection{Sociolinguistic Survey}

Sociolinguistically, Sinhala-English CM was examined in terms of Kachru's (1986) framework. These urban Sri Lankans' use of Kachru's approaches: foregrounding, neutralization, nativization, and hybridization in their spoken discourse reveal the contextual, stylistic, registral, and attitudinal functions of such $\mathrm{CM}$, and prove Sinhala-English CM as the most influential and highly used language-code by the respondents. Here, native Sinhalese speakers' CM is analyzed from a functional perspective and this survey reveals $\mathrm{CM}$ as common phenomena in the spoken variety of urban bilinguals. However, there was a marked distance between the frequency rates of Singlish: Sinhala words in English sentences \& Singrisi: English words in Sinhala utterances due to the fact that the mixed-variety is heavily influenced by English though modelled dominantly on Sinhala. The findings of this survey, similar to those of Wettewe (2009), reveal that this 
mixed-variety that has evolved as a result of CM is undoubtedly the accepted code in the post-colonial Sri Lankan setting today.

\subsection{Language Analysis}

This study provides an adequate interpretation of the structural properties of Sinhala-English CM based on Muysken's (2000) framework for CM. In general, this discussion proves insertion as the major CM strategy in the bilingual spoken discourse, whereas CL is the least used. The analysis shows that integration of English lexical items is largely influenced by the structural convention of Sinhala since it is the dominant variety in this social setting. Interestingly, the constant contact between Sinhala and English has led to the inclusion of such structural elements in the mixed-language in Sri Lanka. Further, the sociolinguistic analysis was validated by this structural interpretation. Interestingly \& similar to the findings of Gunesekera (2010), this study shows that the mixed-code has its own phonological and morpho-syntactic characteristics.

Most significantly, this study, similar to Wettewe (2009), pictures the integration between Sinhala a "low" variety and English a "high" variety. Overall, the mixed-language in Sri Lanka has been a result of frequent language contact and linguistic appropriateness, and has created integration between two typologically different languages. Thus, it is hoped that this study will shed new light on the subject of CM in Sinhala-English bilinguals' spoken discourse in Sri Lanka.

\subsection{Pedagogical Implications}

From a pedagogical perspective, this study suggests $\mathrm{CM}$ as a possible strategy for use in the English as a foreign/second language (EFL/ESL) classroom in Sri Lanka, and is an avenue that requires substantive research in future. The researcher was able to probe important information on Sinhala-English bilinguals' $\mathrm{CM}$ strategies which indicate that the use of $\mathrm{CM}$ can facilitate the second language learning process. Precisely, the mixing of L1 and L2 in utterances produced by L2 learners of English can be a useful element during the learning process. The informants revealed that they were well aware of their L2 attainment though they were not conscious about the CM strategies that had contributed to this language proficiency.

Some findings revealed in this study seem to challenge the theory that teaching English through English makes the whole FLL process authentic and beneficial (Chambers, 1991; Halliwell \& Johns, 1991). Similar to Guthrie (1983), this study suggests in-depth research on whether a class conducted entirely in the target language can result in greater intake or a mixed-code would help learners to become familiarized with the whole TL environment.

The respondents show that they tend to use two languages simultaneously or interchangeably when they are unable to conceive appropriate words within a limited time during their conversation. In such cases, CM has allowed them to express themselves more fluidly and to avoid communicative interruption. In 
the EFL/ESL learning-teaching context in Sri Lanka ELT classrooms are mostly filled with typical Sinhalese students who frequently use their native tongue for communication, and their FL proficiency level is very low. In this environment, English-only classrooms have also been proved unsuccessful since they have constantly led to frustration and anxiety among learners. Therefore, a mixed-code would be a strategy to help these learners. This setting proves what linguistic scholars like Ellis (1994) and Richards-Rogers (2001) argue that exposure to the target language in isolation may not work in every context.

The structural analysis of this study reveals insertion and alternation as major strategies being used for language mixing by the respondents. As they claim, such mixing patterns seem to be helpful when learning new vocabulary and grammar items and to avoid many learning difficulties caused by the lack of comprehensible input in this learning-teaching process. In fact, many techniques have been proposed for vocabulary learning and teaching. The researcher argues that CM will be suitable sometimes to replace the definition method of teaching vocabulary to introduce unknown elements to the FL learner.

Generally speaking, the implications drawn from this study indicated that CM can have many positive functions in the ESL/EFL learning-teaching process. CM can have both metalinguistic and referential functions in this setting. Teachers can utilize CM patterns for paraphrasing words in utterances as in "disguise = wesswalagena" (Sinhala) (respondent 6). During the teaching, when teachers hardly find equals to explain or students find it difficult to absorb the correct meaning, CM can be employed. CM can be a useful device to highlight the importance of a particular linguistic item and make the input more comprehensible to the learner. Often, target language items lack semantically appropriate words to explain such elements or are not readily available. CM can be used to ensure that the instructions given by the tutor are clearly understood and students do not feel confused about what they are learning in the classroom.

In this context, the FL learner will find transferring materials through CM beneficial in the classroom since not all students fully understand the explanations only in English. The researcher suggests that CM can be one of the strategies that EFL/ESL teachers use to accommodate the students' level of proficiency since it makes the learner intake the knowledge provided by the tutor quite comfortably in the classroom.

\section{Conflicts of Interest}

The author declares no conflicts of interest regarding the publication of this paper.

\section{References}

Chambers, F. (1991). Promoting Use of the Target Language in the Classroom. Language Learning Journal, 4, 27-31. https://doi.org/10.1080/09571739185200411

Claros, M. S. C., \& Isharyanti, N. (2009). Code-Switching and Code-Mixing in Internet 
Chatting: Between "Yes", "Ya", and "Si"-A Case Study. The JALT CALL Journal, 5, 67-78. https://doi.org/10.29140/jaltcall.v5n3.87

Disanayaka, J. B. (1998). Understanding the Sinhalese. Colombo: S. Godage \& Brothers.

Ellis, R. (1994). The Study of Second Language Acquisition. Oxford: Oxford University Press.

Fernando, S., Gunesekera, M., \& Parakrama, A. (2010). English in Sri Lanka: Ceylon English Lankan English Sri Lankan English, Colombo: Srr Lanka English Language Teachers" Association.

Gunesekera, M. (2010). The Postcolonial Identity of Sri Lankan English (2nd ed.). Colombo: Vijitha Yapa Publications.

Guthrie, L F. (1983). Contrasts in Teachers' Language Use in a Chinese-English Bilingual Classroom. Washington DC: National Institute of Education.

Halliwell, S., \& Jones, B. (1991). On Target: Teaching in the Target Language. London: Centre for Information on Language Teaching and Research.

Isaac, S., \& Michael, W. B. (1987). Handbook in Research and Evaluation for Education and the Behavioral Sciences. San Diego, CA: Edits Publishers.

Kachru, B. B. (1978). Code-Mixing as a Communicative Strategy. In J. Alatis (Ed.), International Dimensions of Bilingual Education (pp. 107-124). Washington DC: Georgetown University Press.

Kachru, B. B. (1983). The Indianization of English: The English Language in India. Oxford: Oxford University Press.

Kachru, B. B. (1986). The Alchemy of English: The Spread, Functions and Models for Non-Native Englishes. Oxford: Oxford University Press.

Karnalasuriya, H. K. (2008). Code-Switching and Code-Mixing among the Sri Lankan Sinhala Speakers. In Proceedings of the Annual Research Symposium 2008 (pp. 8). Colombo: Faculty of Graduate Studies, University of Kelaniya. http://repository.kln.ac.lk/handle/123456789/7621

Muysken, P. (2000). Bilingual Speech: A Typology of Code-Mixing. Cambridge: Cambridge University Press.

Myers-Scotton, C. (1993). Social Motivations for Code-Switching: Evidence from Africa. Oxford: Clarendon Press.

Richards, J. C., \& Rodgers, T. S. (2001). Approaches and Methods in Language Teaching. Cambridge: Cambridge University Press.

Sailaja, P. (2011). Hinglish: Code-Switching in Indian English. ELT Journal, 65, 473-480. https://doi.org/10.1093/elt/ccr047

Wettewe, C. D. S. (2009). Sinhala-English Code-Mixing in Sri Lanka: A Sociolinguistic Analysis. Utrecht: LOT Publications.

Wettewe, C. D. S. (2011). Discourse Strategies of Sri Lankan Bilinguals. Colombo: Godage International Publishers. 


\section{Appendix 1}

Table 1. Behavioral characteristics of the sample (10 Respondents).

\begin{tabular}{cccc}
\hline Domain & Language $(s)$ used & No. of respondents & Percentage (\%) \\
\hline At home & SE & $10 / 10$ & $100 \%$ \\
Office & SE (mostly) & $9 / 10$ & $90 \%$ \\
\multirow{2}{*}{ Supermarket } & E (not frequently) & $5 / 10$ & $50 \%$ \\
Temple & SE & $10 / 10$ & $100 \%$ \\
\multirow{2}{*}{ Social events } & S & $10 / 10$ & $100 \%$ \\
& SE (mostly) & $9 / 10$ & $90 \%$ \\
\hline
\end{tabular}

S-Sinhala; E-English; SE-Sinhala-English (the mixed-code).

\section{Appendix 2}

\section{Questionnaire for Sociolinguistic Survey}

Answer all questions.

1. Profession:

2. Occupation: GovernmentPrivate.

3. Age:

4. Highest Qualification in Education:

5. Languages that you know:

6. I speak to my parents in: Sinhala English. Mixed-code

7. At home, I speak to my children in:

8. My children (at home) speak to me in:

9. I speak to my seniors at work in:

10. I speak to my juniors in:

11. In official documents, in my office I use:

12. Our official meetings are held in:

13. To speak to my head (institute/office), I use:

14. With my best friend I use:

15. With my relatives I use:

16. Most of my friends speak in:

17. At the temple, church, mosque I use:

18. At the supermarket (when shopping), I speak to those assistants in:

19. When travelling, I speak to those drivers and other personnel in:

20. Mostly, I buy newspapers which are in:

21. I often listen to radio programs when the medium is:

22. Mostly, I read books and magazines which are in:

23. I often watch TV programs in:

24. I like to watch movies that are in:

25. I like TV presenters who use:

26. What is the language-code mostly used by TV/radio presenters:

27. Do you think that the use of Sinhala-English in media is suitable? Yes or No .....Give 
reasons.

28. According to you, what should be the language of the media?

29. Do you think that a mixed-code is the latest trend of your generation?

30. According to you, which language-code is the most neutral to encourage ethnic harmony among people in the country? Why?

31. Have you ever benefitted from CM during your studies in the English as a Foreign/Second Language (EFL/ESL)?

32. Do you think that $\mathrm{CM}$ can be used as a strategy to teach English in the EFL/ESL classrooms in Sri Lanka? Give your reasons.

33. What aspects of EFL/ESL language learning-teaching context in Sri Lanka can be facilitated by CM? How? 